\title{
IMPLEMENTASI MANAJEMEN BERBASIS SEKOLAH DI SDN SUNGAI MIAI 5 DAN SDN SURGI MUFTI 4 DI BANJARMASIN
}

\author{
Hamdan Husein Batubara ${ }^{1}$ dan Dessy Noor Ariani ${ }^{2}$ \\ Email: ${ }^{1}$ huseinbatubara@gmail.com, ${ }^{2}$ dessynoorarianii@gmail.com \\ Fakultas Studi Islam, Universitas Islam Kalimantan MAB Banjarmasin
}

\begin{abstract}
This article aims to explain the description of the implementation of school-based management in SDN Sungai Miai 5 and SDN Surgi Mufti 4 Banjarmasin. The method used is qualitative approach with descriptive type. The data sources of this research are principals and teachers. The method of data collection is interview and observation. The results of this study indicate that the implementation of school-based management at SDN Sungai Miai 5 Banjarmasin is done by involving all school residents in the planning and implementation of school programs, including parents of students. Schools have specialized staff to record and report school finances and assets. The implementation school-based manahement at SDN Surgi Mufti 4 Banjarmasin is done with the principle of togetherness, that is by drivingthe competent teachers to train less competent teachers, mobilize school entrepreneurship activities, and principals teach other teachers by providing a direct example. Thus, the implementation of school-based management requires the support of various parties for improving the learning quality in schools.
\end{abstract}

Keywords: Impelementation; management based on school; MBS; elementary school

\section{PENDAHULUAN}

Bergesernya sistem penyelenggaraan pemerintahan dari sentralistik menjadi desentralistik atau yang dikenal dengan otonomi daerah telah berdampak pada desentralisasi sektor pendidikan. Salah satu program pendidikan yang gencar diperkenalkan pada era otonomi daerah adalah pemberian otonomi yang luas ditingkat sekolah serta partisipasi masyarakat yang tinggi dalam rangka kebijakan pendidikan nasional atau yang dikenal dengan Manajemen Berbasis Sekolah (MBS).

Istilah Manajemen Berbasis Sekolah merupakan terjemahan dari "school-based management". Istilah ini 
pertama kali muncul di Amerika Serikat ketika masyarakat mulai mempertanyakan relevansi pendidikan dengan tuntutan perkembangan masyarakat setempat. MBS merupakan paradigma baru pendidikan yang memberikan otonomi luas pada tingkat sekolah serta pelibatan masyarakat. Otonomi di berikan agar sekolah leluasa mengelola sumber daya serta lebih tanggap terhadap kebutuhan masyarakat (Afandi, 2017).

Menurut Jiyono dalam Rosmalah, manajemen berbasis sekolah berangkat dari ide untuk mengatasi kelemahan institusional yang banyak di lingkungan persekolahan, sebagaimana yang ditemukan dari laporan bank dunia yang menyatakan bahwa ada tiga unsur yang diidentifikasi menjadi penghambat kemajuan pendidikan di Indonesia, khususnya pada tingkat pendidikan dasar, yaitu: 1) manajemen yag terlalu sentralistrik pada tingkat SLTP, 2) terpecah belah dan kakunya proses pembiayaan pada jenjang tersebut, dan 3) manajemen yang tidak efektif pada jenjang sekolah (Rosmalah, 2016).

Alasan penerapan Manajemen berbasis sekolah pada tingkat pendidikan dasarjuga didasari pemikiran bahwa: 1)
Sekolah lebih mengetahui dan memahami kekuatan, kelemaham, peluang, dan ancaman bagi dirinya sehingga sekolah dapat mengoptimalkan pemanfaatan sumber daya yang untuk memajukan sekolah; 2) Sekolah lebih mengetahui kebutuhannya; dan 3) Keterlibatan warga sekolah dan masyarakat dalam pengambilan keputusan dapat menciptakan transparansi dan demokrasi yang sehat (Rosmalah, 2016).

Menurut Rosmalah, penerapan manajemen berbasis sekolah di Sekolah Dasar bertujuan untuk meningkatkan kualitas pendidikan secara umum baik itu menyangkut kualitas pembelajaran, kualitas kurikulum, kualitas sumber daya manusia baik guru maupun tenaga kependidikan lainnya, dan kualitas pelayanan pandidikan secara umum. Sedangkan menurut Siahaan dalam Rosmalah (2016), esensial Manajemen Berbasis Sekolah bertujuan untuk meningkatkan efisiensi mutu relevansi dan pemerataan pendidikan melalui peningkatan partisipasi masyarakat dalam meningkatkan kualitas pelayanan sekolah (Rosmalah, 2016).

$\begin{array}{rrr}\text { Adapun } & \text { dasar } & \text { hukum } \\ \text { pelaksanaan } & \text { manajemen } & \text { berbasis }\end{array}$


sekolah di Indonesia adalah sebagai berikut:

1. Undang Undang Nomor 20 Tahun 2003 tentang Sistem Pendidikan Nasional Pada Pasal 51 Ayat (1) dinyatakan bahwa: "Pengelolaan satuan pendidikan anak usia dini, pendidikan dasar dan pendidikan menengah dilaksanakan berdasarkan standar pelayanan minimal dengan prinsip manajemen berbasis Sekolah/ Madrasah.

2. Undang-Undang Sistem Pendidikan Nasional Nomor 20 Tahun 2006 yang berbunyi "pengelolaan satuan pendidikan anak usia dini, pendidikan dasar, dan pendidikan menengah dilaksanakan berdasarkan standar pelayanan minimal dengan prinsip manajemen berbasis sekolah/ madrasah".

3. Peraturan Pemerintah Nomor 32 Tahun 2013 tentang Perubahan Atas Peraturan Pemerintah Nomor 19 Tahun 2005 Tentang Standar Nasional Pendidikan juga dinyatakan pada Pasal 49 (1) bahwa: "Pengelolaan satuan pendidikan pada jenjang pendidikan dasar dan menengah menerapkan manajemen berbasis sekolah yang ditunjukkan dengan kemandirian, kemitraan, partisipasi, keterbukaan, dan akuntabilitas(Mustuningsih, 2015).

Adapun prosedur implementasi manajemen berbasis sekolah di Indonesia terdiri dari: 1) sosialisasi manajemen berbasis sekolah ke seluruh warga sekolah, 2) menganalisis sekolah dan luar sekolah yang hasilnya berupa tantangan nyata yang harus dihadapi dalam menerapkan manajemen berbasis sekolah, 3) merumuskan tujuan situasional yangi ngin dicapai dari pelaksanaan manajemen berbasis sekolah berdasarkan tantangan yang dihadapi, 4) mengidentifikasi fungsifungsi yang perlu dilibatkan untuk mencapai tujuan situasional, 5) menentukan tingkat kesiapan setiap fungsi dan faktor-faktornya, 6) memilih langkah-langkah pemecahan persoalan yakni tindakan yang diperlukan untuk mengubah fungsi yang tidak siap menjadi fungsi yang siap, 7) membuat rencana jangka pendek, menengah, dan jangka panjang, 8) melaksanakan program-program untuk merealisasikan rencana jangka pendek manajemen berbasis sekolah, dan 9) melakukan pemantauan terhadap proses dan 
evaluasi terhadap manajemen berbasis sekolah (Rosmalah, 2016).

Masalah Manajemen Berbasis Sekolah di Indonesia

Hasil penelitian Mustuningshih mengungkapkan bahwa masalah yang dihadapi dalam implementasi 7 komponen MBS secara berturut-turut adalah: manajemen pembiayaan (100\%), manajemen pendidik dan tenaga kependidikan (88\%), manajemen budaya dan lingkungan sekolah(75\%), manajemen peserta didik (73\%); manajemen sarana dan prasarana $(71 \%)$, manajemen Humas (60\%), dan manajemen pembelajaran (40\%). Hal ini menunjukkan bahwa penerapan MBS di sekolah dasar masih menghadapi berbagai tantangan yang memerlukan solusi yang tepat, khususnya dalam bidang pasrtisipasi masyarakat dalam membantu biaya program-program sekolah (Mustuningsih, 2015).

Hasil penelitian UNESCO dalam Mustuningsih mengungkapkan bahwa masalah implementasi MBS di Indonesia dapat dikelompokkan menjadi 4, yaitu: manajemen sekolah, peran serta masyarakat, kegiatan belajar mengajar dan out put. Ditinjau dari manajemen sekolah, problematika MBS antara lain sekolah belum banyak melibatkan semua pihak atau pihak luar dalam mengambil keputusan (Mustuningsih, 2015).

Menurut hasil penelitian Ihsan, kendala yang dihadapi kepala sekolah dalam implementasi manajemen berbasis sekolah di SD Negeri 62 Kota Banda Aceh adalah pada kesadaran guru terhadap budaya kedisiplinan dan tanggungjawabnya dalam melaksanakan tugas yang diberikan. Oleh karena itu, sosialisasi, keterbukaan, motivasi, dam penyatuan visi sangat mempengaruhi keberhasilan implementasi MBS di Sekolah Dasar (Ihsan; Djailani; AR; Sakdiah Ibrahim, 2014).

Adapun faktor lain dari masalah penerapan MBS menurut Jenni dalam Mustuningsih adalah: 1) kurangnya kemampuan dan pengalaman sekolah untuk mengadopsi dan menerima perubahan, 2) inovasi MBS dibangun tanpa ada perencanaan yang jelas dan jadwal yang pasti, 3) kurang aplikatifnya desain model MBS, 4) jalur birokrasi/komunikasi yang terlalu 
panjang terkadang tidak memberikan pemahaman yang jelas tentang MBS, 5) kurang banyaknya pelatihan/ penataran terkait dengan penerapan MBS atau hasil-hasil pelatihan tidak diterapkan di sekolah sehingga sumber daya manusia di SD belum semuanya memahami langkah-langkah dan prinsip-prinsip MBS (Mustuningsih, 2015).

\section{METODE PENELITIAN}

Penelitian ini menggunakan pendekatan kualitatif jenis deskriptif untuk memperoleh gambaran mengenai implementasi manajemen berbasis sekolah di SDN Sungai Miai 5 dan SDN Surgi Mufti 4 Banjarmasin dari aspek manajemen kurikulum, kompetensi pendidik, peserta didik, lingkungan sekolah, sarana dan prasarana, dan hubungan sekolah dengan masyarakat.

Sumber data penelitian ini terdiri dari data primer dan data sekunder.Sumber data primer yang dipilih dalam penelitian ini adalah kepala sekolah dan guru. Sedangkan sumber data sekunder yang menjadi rujukan peneliti adalah semua dokumen yang dapat melengkapi hasil penelitian ini.Metode pengumpulan data dilakukan adalah wawancaradengan kepala sekolah dan guru sekolah dasar.
Adapun analisis data dalam penelitian kualitatif bersifat berkelanjutan dan dikembangkan sepanjang penelitian. Analisis keabsahan data dilakukan mulai tahapan pengumpulan data, reduksi data, paparan data, dan verifikasi atau pengambilan kesimpulan(Moleong, 2014).

\section{HASIL DAN PEMBAHASAN}

\section{Implementasi Manajemen berbasis} Sekolah Dasar di SDN Sungai Miai 5

\section{Banjarmasin}

Hasil wawancara dengan kepala sekolah SDN Sungai Miai 5Banjarmasin (Hj. Rusmalina, S.PD., M.M) diperoleh informasi bahwa implementasi manajemen berbasis sekolah dalam pengelolaan kurikulum melibatkan dewan guru, pengawas dinas pendidikan, dan paguyuban orang tua, serta mengacu pada peraturan dinas pendidikan dan peraturan yang dikeluarkan pemerintah. Bentuk implementasinya adalah pertemuan bulanan dewan warga sekolah, supervisi kepala sekolah, dan pembinaan yang dilakukan oleh pengawas dinas pendidikan (Hasil wawancara, 5 Desember 2017).

Pengelolaan penerimaan peserta didik baru dilaksanakan merujuk pada 
petunjuk dan teknis penerimaan peserta didik yang diatur oleh pemerintah, yakni dengan mensyaratkan pada umur dan tempat tinggal siswa.Pengelolaan kegiatan ekstrakurikuler dalam manajemen berbasis sekolah melibatkan komite sekolah dalam hal pembiayaan dan dewan guru dalam hal pengkoordinasian dan fasilitator. Adapun kegiatan ekstrakurikuler yang berjalan di SDN Sungai Miai 5 adalah Tadarus Quran, Sholat Dhuha, solat Zuhur berzamaah, dan perayaan hari-hari besar. Selain itu, terdapat juga kegiatan rapat yang bertujuan untuk mensosialisasikan program-program sekolah kepada seluruh warga sekolah (Hasil wawancara, 25 Nopember 2017).

Menurut guru kelas V, manajemen kompetensi guru dilaksanakan dalam bentuk peningkatan partisipasi guru dalam kegiatan KKG dan program pelatihan yang diprogramkan dinas pendidikan. Selain itu, sekolah juga mempersilahkan guru model untuk memberikan pencerahan atau pelatihan kepada para guru (Hasil wawancara, 24 Nopember 2017).

Adapun mengenai manajemen sarana dan prasarana, kepala sekolah telah menunjuk seorang staf yang bertenggung jawab dalam hal pencatatan dan penginventarisan sarana dan prasarana sekolah. Sistem pengadaan atau pembelian sarana sekolah dilakukan berdasarkan hasil rapat bulanan warga sekolah dan mengacu pada RKS sekolah dengan melibatkan semua warga sekolah, termasuk paguyuban orang tua siswa (Hasil wawancara, 24 Nopember 2017).

Hasil observasi penulis terhadap lingkungan sekolah tersebut menunjukkan bahwa sekolah tersebut memiliki fasilitas ruang kelas yang cukup menarik, di dalam kelasnya terdapat pajangan karya siswa, dan bahkan di dalam kelasnya telah terpasang sebuah proyektor yang siap digunakan (Hasil observasi, 28 Nopember 2017).

Keberadaan peserta didik yang berkebutuhan khusus juga telah menjadikan sekolah ini memiliki hubungan yang baik dengan orang tua siswa dalam menyelenggarakan program-program sekolah sehingga sekolah telah memiliki fasilitas belajar dan media pembelajaran yang diyakini mampu membantu guru dalam meningkatkan kualitas proses pembelajaran. Hal ini tentunya sesuai 
dengan yang disampaikan oleh Rosamalah bahwa tersedianya fasilitas belajar yang memadai merupakan tujuan dari pelaksanaan manajemen berbasis sekolah (Rosmalah, 2016).

Berdasarkan hasil temuan di atas, manajemen berbasis sekolah di SDN Sungai Miai 5 telah meningkatkan peran serta masyarakat dalam mensukseskan berbagai program sekolah. Pengelolaan dana sekolah juga telah direncanakan dan dilaporkan secara transfaran dengan melibatkan seluruh warga sekolah. Hal ini tentunya sesuai dengan esensi dan tujuan manajemen berbasis sekolah.

\section{Implementasi Manajemen berbasis} Sekolah Dasar di SDN Surgi Mufti 4

\section{Banjarmasin}

Hasil wawancara penulis dengan kepala sekolah SDN Surgi Mufti 4 Banjarmasin diperoleh informasi bahwa peran kepala sekolah dalam manajemen kurikulum bertugas sebagai pengawas dan pemberi contoh, dan motivasi kepada guru untuk melaksanakan pembelajaran yang bervariasi di dalam dan di luar sekolah serta memanfaatkan lingkungan sekitar sebagai sumber belajar bagi siswa, seperti makam pahlawan, sungai, dan taman (Hasil wawancara, 27 Nopember 2017).

Menurut Guru kelas, manajemen berbasis sekolah dalam penerapan kurikulum dilakukan dengan melibatkan dewan guru dan orang tua siswa dalam bentu pertemuan. Kurikulum yang diterapkan di SDN Surgi Mufti 4 Banjarmasin adalah kurikulum KTSP untuk kelas 3 dan 6 dan kurikulum 2013 untuk siswa kelas 1, 2, 4, dan 5 (Hasil wawancara, 28 Nopember 2017).

Menurut hasil wawancara dengan kepala sekolah, manajemen pengembangan kompetensi guru di sekolah ini dilakukan dengan menugaskan guru yang telah mengikuti pelatihan untuk melatih guru-guru yang belum bisa pada saat pertemuan dewan guru, dan mendorong guru untuk aktif dalam kelompok kerja guru (KKG) (Hasil wawancara, 27 Nopember 2017).

Manajemen hubungan sekolah dengan komite sekolah dilakukan dengan cara melibatkan orang tua siswa dalam merencanakan dan melaksanakan beberapa program sekolah, sepertipenggalangan dana kegiatan ekstrakurikuler, pembangunan pagar sekolah, dan beberapa program sekolah lainnya. Namun, menurut kepala 
sekolah, partisipasi masyarakat terhadap program sekolah menurun sejak maraknya pemberitaan pungutan liar di sekolah. Hal ini berakibat pada berkurangnya program-program ekstrakurikuler di sekolah (Hasil wawancara, 1 Desember 2017).

Untuk mengatasi masalah pembiayaan kegiatan sekolah, sekolah terkadang harus meminjam tabungan siswa untuk membiayai kegiatan sekolah dan gaji guru honorer sebelum pencairan dana BOS tiba. Selain itu, sekolah juga menggerakkan kegiatan wirausaha bagi siswa, seperti membuat motif dan merajut kain sasirangan (Hasil wawancara, 1 Desember 2017).

Menurut guru SDN Surgi Mufti 4, manajemen berbasis sekolah diterapkan dengan mengutamakan asas kebersamaan. Misalnya, guru yang kurang kompeten diajari oleh guru yang lebih kompoten, begitu pula, guru yang kurang disiplin diberikan teguran secara tertutup dengan cara mendengarkan curhatannya dan kemudian mencari solusi yang terbaik untuk membantu guru tersebut agar tidak mengulangi kesalahannya (Hasil wawancara, 28 Nopember 2017).
Katrunnanda, S.Pd., MM, pengawas sekolah dasar di Banjarmasin,mengungkapkan bahwa berita tentang ancaman pungutan liar di sekolah telah membuat kepala sekolah takut dalam melibatkan peran serta orang tua untuk berpartisipasi dalam kegiatan sekolah. Hal tersebut berimplikasi pada turunnya partisipasi masyarakat dalam mendukung program-program yang dapat meningkatkan prestasi peserta didik. Padahal, partisipasi masyarakat atau orang tua siswa terhadap kegiatan sekolah sebenarnya masih dibenarkan dalam bentuk sumbangan dan hibah. Akan tetapi, sebagian sekolah negeri tampak enggan untuk mengelola dana yang bersumber dari masyarakat (Hasil wawancara, 22 Nopember 2017).

Berdasarkan temuan tersebut, salah satu masalah yang dihadapi SDN Surgi Mufti 4 Banjarmasin dalam menerapkan manajemen berbasis sekolah adalah kekhawatiran kepala sekolah terhadap hukuman pungutan liar ketika mengajak dan menerima sumbangan dari orang tua siswa dan masyarakat. Meskipun, sumbangan jelas berbeda dengan jenis pungutan yang dilarang, tetapi isu tersebut telah membuat tingkat kerjasama sama 
sekolah dan masyarakat menurun (Hasil wawancara, 28 Desember 2017).

Berdasarkan uraian di atas, dapat dikatakan bahwa salah satu manajemen sekolah dasar yang paling bermasalah adalah pada manajemen keuangan sekolah. Hal ini antara lain dikarenakan sebagian sekolah dasar tidak memiliki staf khusus yang menangani tentang pencatatan dan pelaporan keuangan sekolah.

Hasil temuan serupa juga dikemukakan Sahril Muhammad bahwa dalam hasil penelitiannya yang menunjukkan bahwa sekolah sekolah dasar Islam Insan Kamil Bacan Kabupaten Halmahera Selatan masih mengalami kendala pada keterbatasan sumber pembiayaan sekolah dikarenakan sebagian besar masyarakat dan pelaku pendidikan lainnya belum sepenuhnya memahami pentingnya program manajemen berbasis sekolah (Muhammad, 2017).

\section{KESIMPULAN}

Berdasarkan pembahasan tentang implementasi manajemen berbasis sekolah di atas dapat disimpulkan sebagai berikut:
1. Implementasi manajemen berbasis sekolah di SDN Sungai Miai 5 Banjarmasin dilakukan dengan melibatkan seluruh warga sekolah dalam perencanaan dan pelaksanaan program-program sekolah, termasuk orang tua siswa. Untuk menertibkan manajemen sarana dan prasarana, sekolah ini telah memiliki staf khusus bagian pencatatan dan pengarsipan aset sekolah.

2. Implementasi manajemen berbasis sekolah di SDN Surgi Mufti 4 Banjarmasin dilakukan dengan asas kebersamaan, yakni dengan memberikan fasuilitas kepada guru yang kompeten untuk berbagi ilmu dengan guru yang kurang kompeten, menggerakkan kegiatan wirausaha sekolah, dan kepala sekolah mengajari guru lainnya dengan memberikan contoh langsung.

\section{DAFTAR PUSTAKA}

Afandi, S. A. (2017). Governability Implementasi Manajemen Berbasis Sekolah di Sekolah Dasar Negeri 18 Pekanbaru Tahun 2013-2015. JOM FISIP, 4(1).

Ihsan; Djailani; AR; Sakdiah Ibrahim. (2014). Penerapan Manajemen Berbasis Sekolah dalam Meningkatkan Mutu Pendidikan di 
SD Negeri 62 Kota Banda Aceh. Jurnal Administrasi Pendidikan Pascasarjana Universitas Syiah Kuala, 4(2), 12-20.

Moleong, L. J. (2014). Metode Penelitian Kualitatif. PT. Remaja Rosda Karya. Bandung.

Muhammad, S. M. R. (2017). Implementasi Manajemen Berbasis Sekolah untuk Meningkatkan Mutu Sekolah Dasar Islam Insan Kamil Bacan Kabupaten Halmahera Selatan. Edukasi: Jurnal Pendidikan, 15(1), 610-620.

Mustuningsih. (2015). Masalah Implementasi Manajemen Berbasis Sekolah di Sekolah Dasar. Manajemen Pendidikan, 24(6), 498-505.

Rosmalah. (2016). Hakikat Implementasi Manajemen Berbasis Sekolah. Jurnal Publikasi Pendidikan, VI(1), 64-76. 